\title{
NARRATIVAS DISTÓPICAS COM PROTAGONISMOS JUVENIL: MEMÓRIA E INSTINTO DE RESISTÊNCIA EM THE MAZE RUNNER
}

Tânia SARMENTO-PANTOJA ${ }^{1}$

Universidade Federal do Pará (UFPA)
Resumo: Este estudo apresenta duas categorias - a memória ausente e o instinto de resistência - com vistas a analisar deteminadas caraterísticas da ficção distópica, destinada aos jovens adultos. Analisa The Maze Runner (romance e filme homônimos) a fim de estabelecer o estudo de caso, na medida em que acentua a associação entre distopia e ficção científica, com particular atenção aos elementos da biopunk fiction.

Palavras-Chaves: Distopia. Biopunk. Ficção. Memória. Resistência. James Dashner
Abstract: This study presents two categories - absent memory and resistance instinct - in order to analyze the distinguished characteristics of dystopian fiction, aimed at young adults. It analyzes "The Maze Runner" (homonymous novel and film) to establish the case study as it emphasizes the association between dystopia and science fiction, with particular attention to the elements of biopunk fiction.

Keywords: Dystopia. Biopunk. Fictio. Memory. Resistance. James Dashner

\footnotetext{
1 Possui graduação em Letras pela Universidade Federal do Pará (1995), mestrado em Letras pela Universidade Federal de Pernambuco (1999) e doutorado em Estudos Literários pela Universidade Estadual Paulista Júlio de Mesquita Filho (2005). Atualmente, é professora Associada I I da Universidade Federal do Pará atuando na Graduação e na Pós-Graduação.
} 


\section{Introdução}

The Maze Runner ${ }^{2}$ (2010), filme dirigido por Wes Ball, com base no roteiro de Noah Oppenheim, tem o romance homônimo, de James Dashner (2009), como roteiro original. Livro e filme homônimos narram a história de um grupo de adolescentes, inicialmente todos do sexo masculino, com variações étinicas e de idade, que vão desde a infância até o jovem adulto. Esses indivíduos vivem em uma espécie de comunidade no que parece ser a fração de uma floresta, onde há uma clareira cercada por todos os lados por um gigantesco labirinto, que abre suas portas pela manhã e as fecha à noite. No livro, James Dashner descreve esse labirinto como um conjunto de blocos de pedra, dispostos e organizados como se fossem gigantescas caixas quadradas. Thomas, ao deparar-se pela primeira vez com a visão do labirinto, o vê exatamente dessa forma:

A maze? In front of him, through the East Door, he could make out passages leading to the left, to the right, and straight ahead. And the walls of the corridors were similar to those that surrounded the Glade, the ground made of the same massive stone blocks as in the courtyard. The ivy seemed even thicker out there. In the distance, more breaks in the walls led to other paths, and farther down, maybe a hundred yards or so away, the straight passage came to a dead end. ${ }^{3}$ (DASNHER, 2009, p. 18).

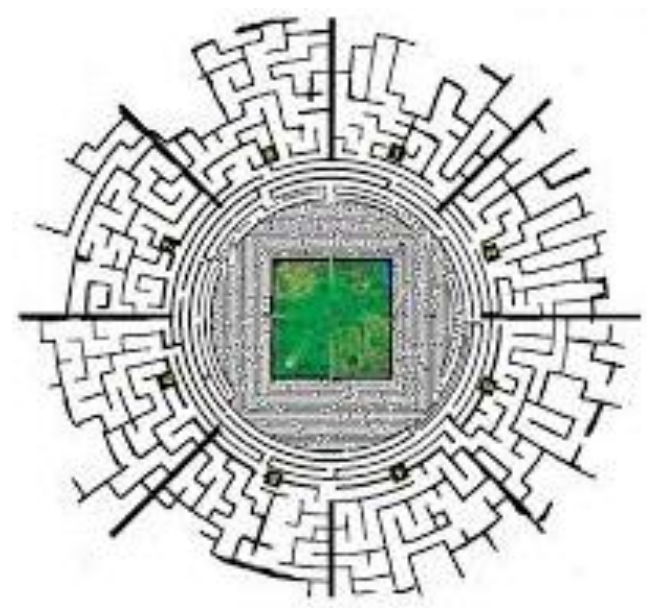

\footnotetext{
${ }^{2}$ No Brasil e em Portugal, Maze Runner: Correr ou Morrer

3 Em tradução livre: "Thomas o ignorou, mais interessado do que nunca no lado de fora da Clareira. Um labirinto? A frente dele, ao olhar através da porta leste, conseguia distinguir passagens que levavam à esquerda, à direita e em linha reta adiante. $\mathrm{E}$ as paredes dos corredores eram semelhantes àquelas que cercavam a Clareira, o chão feito dos mesmos blocos de pedra maciça, tal como no pátio. A hera parecia ainda mais densa lá fora. Ao longe, trilhas entre as paredes levavam a outros caminhos, e mais abaixo, talvez cem metros ou mais, a passagem reta chegava a um beco sem saída"
} 
Labirinto com Clareira e Floresta ao centro ${ }^{4}$

Como se não bastasse parecerem assustadores em função da aparência os blocos de pedra descomunais ainda se movem: "they just move" (DASHNER, 2009, p.18), diz Chuck a Thomas 5 .

A cada trinta dias a Clareira recebe um novo morador. Os rapazes são nela inseridos através de uma escotilha com elevador, mas eles (e, incialmente, também o leitor/expectador) não sabem como e nem porque razões foram introduzidos nesse lugar. E não sabem porque não lembram: todos chegam àquele lugar em completo estado amnésico.

A história é narrada principalmente em função e pela perspectiva do protagonista, chamado Thomas, e a narrativa inicia com sua chegada à Clareira. O Labirinto, e ao centro dele, a Floresta e a Clareira formam o complexo em que boa parte das ações narrativas são desenvolvidas. Como já referido o Labirinto possui paredes móveis e sua estrutura muda o tempo todo, além disso há em seu interior criaturas horríveis, uma espécie de animal simbiótico - máquina revestida de material biológico (sangue, músculos e pelagem), extremamente hostil e de hábitos noturnos, que os adolescentes chamam de verdugos (griers), o que torna o Labirinto um espaço proibido à circulação humana no período da noite.

É interessante salientar esse Labirinto como o entrelugar entre dois locus, dois universos: o conhecido e o desconhecido. Em Correr ou Morrer os jovens logo descobrem que o Labirinto é também um mapa: sua arquitetura evoca os Domus Daedali, construção complexa e em constante mutação. Os movimentos do Labirinto são planejados: se fazem em níveis ou etapas. Para descobrir e compreender a lógica de seus movimentos os jovens precisam agir como se estivessem em um game não virtual: apostam corrida contra o tempo e, sobretudo, contra a ignorância.

Sabemos que o imaginário do Labirinto ora indica prisão ou refúgio do monstruoso (como na cultura clássica), ora espaço da ociosa diversão (como o jardim do

\footnotetext{
${ }^{4}$ Mapa do Complexo (Labirinto com Clareira e Floresta ao centro) descrito por James Dashner em The Maze Runner (2009). Disponível em: http://thebrokentoys083.wixsite.com/thebrokentoys/singlepost/2016/05/20/Resenha-Maze-Runner-\%E2\%80\%93-Correr-ou-Morrer-\%E2\%80\%93-Livro-Um ${ }^{5}$ Em entrevista à Entertainment Weekly Ball diz que, para o filme, pensou o Labirinto como uma estrutura semelhante à máquina de um relógio gigante, com o intuito de criar o efeito de mobilidade, já destacado no romance, mas sem abrir mão dos elementos que compõem a mirada de Thomas, tal como pensada por Dashner.
} 
Palácio de Versalhes). Em Correr ou morrer ao mesmo tempo em que faz a função de portal ou barreira de uma prisão o Labirinto pode também significar o encontro com os verdugos e consequentemente a morte e, nesse sentido, remete ao paradigma clássico. Para vencê-lo não basta ter coragem e ser excelente corredor. É preciso também solucionar os enigmas por trás dos movimentos da estrutura que permitem reconfigurações no cenário do Labirinto, algo a ser resolvido pelo protagonista. O desafio do Labirinto, desse modo, implica uma dupla navegação labiríntica: espaço e pensamento labiríntico.

Desse modo, o Labirinto funciona ao mesmo tempo como fronteira final de uma experiência concentracionária e poderoso mecanismo de contenção, que impede os jovens de descobrirem o que há além dele. A Clareira e a Floresta, localizados ao centro, são como uma bolha de proteção, um lugar onde os jovens se sentem seguros em relação ao que há no Labirinto, mesmo desconhecendo o todo existente para além daqueles muros. A rotina na Clareira resume-se à busca por condições mínimas de sobrevivência: plantar, colher, preparar alimentos, construir abrigos e bunkers com resíduos retirados da floresta.

É importante salientar que a rotina de tarefas na clareira é determinada pelo cooperativismo. Os garotos são divididos por funções na comunidade. Essa distribuição é feita de acordo com as habilidades que parecem mais significativas em cada um. Há lideranças no interior do sistema de convivência, mas as lideranças se justificam em razão das tarefas organizarem-se com base naquelas habilidades que os jovens manifestam com maior destaque: dessa forma há alguns que lideram a organização interna da comunidade, há outros responsáveis pela segurança e regras de convivência e há um pequeno grupo que tem grande destaque na história: são os corredores. Cabe a eles, liderados por Minho, percrustar e mapear o labirinto nos horários em que é possível transitar por ele. Os corredores precisam ser fisicamente hábeis e ágeis para empreender longas corridas no interior do Labirinto e possuir memória fotográfica para registrarem cuidadosamente cada espaço e detalhe encontrado, bem como, evadirem-se a tempo dos perigosos contornos que o cenário pode constituir quando os gigantescos muros movem-se e os verdugos surgem do limbo.

É também reconhecível nessa estrutura social o paradigma do acampamento, pois tudo na Clareira é provisório: todos os objetos e condições são improvisados, marcados pela precariedade e pela economia da sucata e do resíduo. Essa vida provisória é regida 
por ritos e um sistema de regras formulado pelos próprios jovens e baseado na observação do ambiente em redor, aí incluído o funcionamento do Labirinto. Aquele que as transgride é banido da Clareira e sujeito a uma cruel punição, pois é obrigado a adentrar no Labirinto nos horários em que os verdugos estão ativos. O que significa morte certa.

Em vista dessas condições as narrativas da franquia The Maze Runner podem ser compreendidas como narrativas distópicas.

\section{A ficção distópica}

No campo médico distopia corresponde ao deslocamento ou anomalia de um órgão em virtude de uma fragilidade estrutural. Etimologicamente, distopia provém do grego: dis (mal), "anormal" ou "defeituoso", e topos (lugar). Considerando essas dimensões em outro estudo entendo por distópico "a situação ou o lugar, em que as condições, norteadoras das relações humanas, podem se apresentar adversas por se encontrarem deterioradas, inóspitas ou cambiantes ou, ainda, sujeitas a um sentido de paralisia” (SARMENTO-PANTOJA, 2005, p.111). Na opinião de Patrick Mooney (2004, p. 2), a maioria dos romances distópicos ao fazerem emergir o devir consideram vitalmente importante a relação entre a experiência e a degradação da humanidade, e por isso costumam direcionar seu foco especulativo para a constituição das relações entre poder, linguagem e individualidade.

No campo literário alguns estudiosos (BOOKER, 1994; MOYLAN, 2000; MOONEY, 2004) indicam pelo menos três aspectos fundamentais para que determinada ficção possa ser considerada ficção distópica: a especulação acerca da constituição do indivíduo ou da individualidade, o debate sobre a gênese das formas de poder, a acomodação da linguagem ao poder repressivo.

Conceitualmente, a distopia pode ser definida como "uma crítica dissimulada a todas as tentativas de imposição de um poder absoluto", independentemente de sua gênese, bem como "todas as tentativas de pré-determinação de um mundo novo onde apenas a felicidade e a ordem sejam possíveis" (CEIA, 2004, p. 6). Nesse sentido, uma condição distópica pode ser apregoada como uma boa ideia para solucionar uma condição negativa que ser quer transcendida, quando na verdade não passa de outro inferno mascarado de paraíso. A noção de um falso paraíso vendido como uma ilusão - ou utopia 
- bem torneada para convencer incautos, de fato, é uma das referências importantes para a compreensão de como uma condição distópica nasce e progride (SARMENTOPANTOJA, 2005, p. 111).

Nesse sentido, sem dúvida, a ficção distópica é um dos locus literários por excelência em que se descortina o Mal. Tom Moylan (2000, p.xi) afirma que a ficção distópica do século XX esteve muito bem nutrida por terrores próprios dessa época, como a repressão estatal, as guerras, os genocídios, os ecocídios, a exploração de seres humanos. O raciocínio de Moylan mostra um conjunto de temas paradigmáticos em que a vida se apresenta sob grande ameaça, com grande possibilidade de sofrer terríveis revezes. Desse modo, nesse contexto, vejo ser possível afirmar também a proximidade entre a distopia e a catástrofe, esta última, consolidando-se como um importante fundamento da ficção distópica, independente de qual seja o tempo da narrativa.

Fredric Jameson (1997, p. 67-68), em digressão sobre o assunto, localiza a experiência catastrófica das distopias sempre em um tempo por vir, ou como ele mesmo salienta: "a distopia é, sempre e essencialmente, aquilo que na linguagem da crítica de ficção científica se chama de "romance do "futuro próximo"” que conta "a história de um desastre iminente - ecologia, superpopulação, praga, seca, cometa desviado ou acidente nuclear" na qual o futuro é sempre o presente da narrativa. Ao discordar parcialmente de Jameson penso que a ficção distópica não depende exclusivamente dessa relação encapsulada com a ficção científica, como nos termos desse "romance do "futuro próximo". Sem dúvida o "futuro próximo" se expressa como uma grande vertente da ficção distópica, entretanto, é possível termos uma ficção distópica cuja organização especulativa esteja direcionada para outras realidades, sem que necessariamente o distanciamento seja produto de temáticas ou condições miméticas próprias da ficção científica.

Por sua vez, Keith Booker (1994, p.4) também acredita ser o paradigma da ficção científica fundamental para se entender a ficção distópica, por conta do conceito de desfamiliarização. De acordo com Booker, na desfamiliarização (ou truque do estranhamento), o fato de o presente da narrativa permitir que a história contada se localize em um tempo ou realidade ainda desconhecidos - porque se apresentam no futuro ou em uma realidade alternativos - permite que determinadas perspectivas acerca de práticas sociais e políticas problemáticas, conhecidas, possam ser avaliadas como sendo 
privilégio para alguns ou consideradas naturais e inevitáveis para outros, enquanto se mostram violadoras para terceiros. Conforme avalio o termo-chave na categorização proposta por Booker, nessa teorização, é o distanciamento:

\begin{abstract}
um distanciamento espaço-temporal em relação ao mundo tal como o conhecemos, aproxima as distopias das ficções científicas e, ao mesmo tempo, define a diferença entre elas, pois a ficção distópica, em geral, difere da ficção científica pela sua intenção de colocar-se como crítica social e política em relação a um determinado paradigma da governabilidade e seus impactos sociais e políticos. Nesse sentido, enquanto, por sua vez, muitas das ficções científicas tendem a ressaltar positivamente certos aspectos especialmente relacionados à noção de progresso tecnológico, o foco distópico aponta para a crítica sombria da cultura contemporânea, principalmente quanto à mistificação de certos princípios paradigmáticos, como o emprego desumanizador da tecnologia e de certos aspectos do consumismo e da individuação. (SARMENTO-PANTOJA, 2005, p.113)
\end{abstract}

Mais uma vez, porém, é preciso dizer que a ficção distópica não precisa estar necessariamente integrada aos temas da ficção científica para que a desfamiliarização ganhe expressão, uma vez que o distanciamento - argumento de base da desfamiliarização - pode ser provocado por outras vias de acesso de natureza temática ou estética, a exemplo do insólito, da abjeção ou do terror. O terror, por exemplo, pode ser mediado pelo "medo do estado, da violência, da máquina, da modificação biológica ou da destruição do meio ambiente" (RODRIGUES, 2015, p. 34), ao mostrar que decididamente qualquer forma de terror é hostil.

Considero, contudo, que a grande engrenagem que põe a funcionar a ficção distópica é sem dúvida a especulação sobre o poder. Nela, a especulação sobre o poder, independemente de qual seja o tipo de realismo aplicado, pode estar representada por um governante autoritário, uma instituição governamental coerciva, uma corporação controladora, entre outras possibilidades. Desse modo, quando o poder não está nas mãos do estado - ou do que o representa - pode ser facilmente encontrado em um organismo representativo de uma determinada forma de governabilidade, como é o caso de uma instituição cuja base de ação é a da economia predadora, como por exemplo, uma corporação empresarial, entretanto, independente do caminho escolhido para dramatizar o poder, o efeito é o mesmo: o indivíduo sempre se apresenta esmagado e a liberdade restringida.

De qualquer modo, ao estabelecer uma relação especulativa sobre o poder observo que a ficção distópica tende também a refletir sobre a diluição do indivíduo, afinal, a 
construção de um "mundo ideal” sempre irá comportar a coerção àquele que não quiser e/ou não suportar a estrutura desse universo. Nesse sentido, ainda como resultado da especulação sobre o poder, a crítica à domesticação voltada ao ajustamento vem a ser também um traço distintivo das distopias. É que as distopias buscam mostrar que no lugar do justo ou ao tomar como justificativa o justo, o objetivo mesmo é sempre o ajustamento do indivíduo. Essa, aliás, me parece ser a constituição norteadora da franquia The Maze Runner.

Várias dessas constituintes não estão ao largo das distopias com protagonismo infanto-juvenil (ou do jovem adulto). Nelas, a experiência catastrófica, quase sempre matizada pela forma da ficção científica, traz à cena universos em que a expropriação, o assujeitamento e a catástrofe caminham juntas. De fato, para Paula Martins Rodrigues, autora da dissertação de Mestrado intitulada A narrativa distópica juvenil: um estudo sobre Jogos Vorazes e Divergente:

Até a metade do século XX, boa parte das grandes distopias havia sido produzida: o conto de E. M. Foster, "The Machine Stops" (1909), aparece como uma das primeiras amostras da preocupação com a demasiada dependência do homem em relação à máquina. No entanto, para muitos, é Nós (1924), do russo Zamyatin, o inaugurador das distopias. O romance apresenta um futuro no qual uma sociedade aparentemente perfeita e igualitária retira o livre-arbítrio de seus habitantes, controlando-os como máquinas e levando-os a uma vida oprimida e estagnada. A obra, crítica do socialismo russo, serviu de influência para Admirável mundo novo e 1984, que levam muitos traços dela. Nós pode ser visto, em muitos aspectos, como um paradigma. (RODRIGUES, 2015, p.28).

\section{The Mazze Runner e a relação entre ficção científica e a distopia: paradigmas envolvidos}

A franquia The Mazze Runner é uma sextologia composta de uma trilogia e três prequências. Ao observarmos as narrativas constituidoras da trilogia, respectivamente Correr ou morrer (2009), Prova de Fogo (2010) e a Cura Mortal (2011) ${ }^{6}$ e as três narrativas que na sextologia servem de prelúdio à trilogia, ou seja, as prequências Ordem

\footnotetext{
${ }^{6}$ A filmografia homônima corresponde, respectivamente, a Correr ou morrer (2014), Prova de Fogo (2015) e a Cura Mortal (2018).
} 
de Extermínio (2012), Arquivos (2013) e o Código da Febre (2016), vemos que por trás de todas as ações está a corporação conhecida como C.R.U.E.L, uma gigantesca indústria de reengenharia genética e manipulação biológica.

O mundo ia muito bem, em um tempo indefinido no futuro, quando chamas solares muito potentes atingem o planeta Terra e destroem o meio ambiente e parte da humanidade. Nesse mundo com ecossistema já encolapsado e em completa desintegração social, surge um vírus chamado "Fulgor", que ataca as estruturas neurológicas do cérebro do portador levando-o progressivamente a uma forma de demência que o torna irracional, extremamente agressivo e com aparência e comportamento zumbilóides.

Há suspeita de que o vírus foi criado em laboratório com fins lucrativos e nesse contexto provavelmente a corporação C.R.U.E.L é a responsável por sua disseminação, ao mesmo tempo em que demanda pela cura e, nesse processo, institucionalizasse como poder absoluto. É exatamente esse argumento estruturante, predisposto a encenar - e examinar - as manipulações genéticas e éticas exercidas por um poder excessivo em um universo derruído, que encaminha a franquia para o paradigma da biopunk fiction, ainda que um dos limites de seu enredo esteja o flerte com a solar punk fition.

Desse modo, enquanto narrativa The Mazze Runner compõe-se como um conjunto de ficções distópicas que dialogam com a ficção científica. Nesse processo, Correr ou Morrer - que analiso de forma mais detida - converge em apropriação para as duas subcategorias da ficção científica referidas, a solar punk fiction e a biopunk fiction, em um jogo de oposição que evidencia os parâmetros desta última, como pronunciado engate à condição distópica.

A solarpunk fiction surge no início dos anos 2000 como paradigma alternativo aos mundos apocalípticos das narrativas distópicas, ao apostar no sucesso das políticas voltadas a melhoria da qualidade de vida, na existência pacífica e ecologicamente equilibrada. Para Connor Owens:

Solarpunk is a (mostly) aesthetic-cultural and (sometimes) ethical-political tendency which attempts to negate the dominant idea which grips popular consciousness: that the future must be grim, or at least grim for the mass of people and nonhuman forms of life on the planet. Looking at the millennia-old rift between human society and the natural world, it sets as its ethical foundation the necessity of mending this rift, transforming our relation to the planet by transcending those social structures which lead to systemic ecocide. 
It draws a lot from the philosophy of social ecology, which also focused on mending this rift by restructuring society to function more like ecology: non-hierarchical, cooperative, diverse, and seeking balance ${ }^{7}$ (OWENS, 2019, p. 3, grifos meus).

No curto prefácio de Solarpunk, uma antologia de narrativas breves, escritas em português, Gerson Lodi-Ribeiro, também o organizador da antologia, diz que "na Solarpunk, em virtude da imposição da abordagem de temáticas ao emprego das energias ditas "verdes" ou alternativas, a maior parte dos textos é ficção científica autêntica, com cenários futuristas e seus ícones e arquétipos característicos" (LODI-RIBEIRO, 2012, p. $3)$.

Frente a essas indicações penso que a solarpunk fiction corresponde à ficção científica especialmente vinculada à composição de uma utopia ora baseada no uso com sucesso de recursos renováveis e/ou autossustentáveis, ora como narrativa de recomposição frente a um desastre eco-social, em ambos os casos com possibilidade de se lançar a uma realidade alternativa e/ou futurista, de modo a destacar-lhe a positividade de suas bases e interesses. Nesse sentido, é possível compreender a Clareira de Correr ou Morrer como um exemplo reduzido do paradigma da solarpunk fiction. Considerando os aspectos salientados por Owens, até a chegada do protagonista, os garotos vivem em um sistema espelhado neste paradigma: uma existência calcada na (quase) ausência de hierarquias, no cooperativismo, na diversidade, e em um (aparente) pacifismo. Contudo, o predomínio do paradigma é mesmo o da biopunk fiction, como se percebe adiante.

Por sua vez, "biopunk", como conceito, foi introduzido no âmbito da pesquisa acadêmica por Brian McHale (1992), embora houvesse anteriormente menções ao termo em textos de divulgação artística $^{8}$ e um de seus principais fundamentos - temáticas

\footnotetext{
${ }^{7}$ Em tradução livre: "O Solarpunk é uma tendência (principalmente) estético-cultural e (às vezes) éticopolítica que tenta negar a ideia dominante no senso comum: a de que o futuro deve ser sombrio, ou pelo menos sombrio para as pessoas e para as formas de vida não humanas que habitam o planeta. A ruptura milenar entre a sociedade humana e o mundo natural, estabelece como fundamento ético a necessidade de consertar essa ruptura, ao transformarmos nossa relação com o planeta, e ao transcendermos as estruturas sociais que levam ao ecocídio sistêmico.

Ela é em muito devedora da filosofia que dá base à ecologia social, também concentrada em consertar essa ruptura ao reestruturar a sociedade de forma a fazê-la funcionar do mesmo modo que a ecologia: não hierárquica, cooperativa, diversa e buscando o equilíbrio".

8 Lars Schmeink (2014b, p.33) refere-se a um manifesto de 1990, de Eva Hauser, escritora do biopunk tcheco.
} 
baseadas em questões biológicas - já fosse objeto de consideração da crítica literária especializada desde 1977 (PARKER apud SCHMEINK, 2014a, p. 8).

Também considerado subgênero da ficção científica o biopunk discute, sobretudo, a condição pós-humana e as relações que esta estabelece com aspectos caros a manipulação biológica, em particular as que integram conhecimentos e o debate ético provenientes da engenharia genética: "Biopunk reflects this shift of scientific prominence in general discourses and provides a creative exploration not only of the technoscientific possibilities of further progress in genetics, but also of the environmental and social consequences that they might bring with them"9 (SCHMEINK, 2014b, p. 34).

Segundo Schmeink (2014a; 2014b) o biopunk apresenta duas grandes vertentes: de uma parte tem-se uma "trans-humanist fantasy of escape from the finite materiality of the enfleshed self"'10 (BRAIDOTTI, 2013, apud SCHMEINK, 2014b, p. 34) encaminhando-se para a melhoria, por meio de mecanismos tecnocientíficos, de um corpo considerado deficiente ou limitado (NAYAR apud SCHMEINK, 2014b, p. 35) ${ }^{11}$. De outra parte tem-se um pós-humanismo crítico (NAYAR apud SCHMEINK, 2014b, p. 35) em que é colocado em pauta o compartilhamento de ecossistemas, processos de vida, desenvolvimento de material genético, entre humanos e entre humanos e outras espécies, incluindo-se aí as alienígenas, as não-bióticas e mesmo as simbióticas, e as possíveis repercussões positivas e não positivas provenientes de tais processos, dentre as quais ganha destaque aquelas presentes em narrativas em que é preciso enfrentar a radical supressão ou objetificação da alteridade, tornada o objeto de exploração ${ }^{12}$.

Na relação incontestável com o paradigma da biopunk fiction cabe salientar em toda a franquia The Maze Runner pelo menos três topoi: a manipulação da engenharia genética que resulta na criação de um vírus mortal; a redução dos corpos humanos a objetos de manipulação genética; a criação e produção de uma quimera: o verdugo. Todos esses temas voltam-se ao debate sobre a condição pós-humana.

\footnotetext{
${ }^{9}$ Em tradução livre: “O biopunk reflete essa mudança de proeminência científica nos discursos gerais e proporciona uma exploração criativa não apenas das possibilidades tecnocientíficas de progresso adicional na genética, mas, sobretudo, das consequências ambientais e sociais que elas podem trazer consigo".

${ }^{10}$ Em tradução livre: "fantasia trans-humanista para escapar da materialidade finita de um eu fragilizado"

11 O paradigma indicado no estudo consultado é Neuromancer, de William Gibson. Penso que não podemos esquecer aqui do filme Gattaca.

12 Segundo Nayar (apud SCHMEINK, 2014, p. 35) é o que sucede em Resident Evil. Contudo, outro paradigma digno de nota, nesta segunda vertente, seriam alguns filmes da franquia Alien.
} 
Tanto em Correr ou Morrer, quanto em Prova de Fogo, respectivamente, primeira e segunda narrativa da trilogia, nota-se a total ausência de uma estrutura estatal e ao mesmo tempo é clara a presença da corporação C.R.U.E.L como projeção do estado coercitivo, seja pelo gigantismo do poder que detém, que inclui a militarização da segurança, seja pelo tratamento concentracionário, imposto aos jovens residentes da Clareira.

Na medida em que as narrativas avançam sabemos que cada um dos jovens são especiais, porque seu sangue, depois de geneticamente manipulado, pode conter a chave para a imunidade ao vírus "Fulgor" em um processo biológico que a C.R.U.E.L ainda não consegue dominar. Em função dessas circunstâncias a corporação legisla e age sobre a existência dos sobreviventes, tratando-os como cobaias: as crianças cujo sangue é especial são totalmente apartadas do convívio familiar, levadas para uma vida em laboratório, onde lhes roubam suas memórias e consequentemente suas identidades, com a finalidade de terem seus organismos estudados. Ao entrarem na puberdade, como parte de um experimento que visa investigar como a imunidade ao vírus reage em ambiente estéril, são transferidos para o complexo formado pela Floresta, a Clareira e o Labirinto.

Nesse contexto avalio ser necessário destacar dois aspectos: a memória ausente, e as relações entre o instinto de rebanho e o instinto de resistência

\section{A memória ausente}

Ao serem lançados pela escotilha os adolescentes despertam de uma espécie de torpor e ao acordarem todos estão sem a memória do tempo anterior à entrada na Clareira. A vida toda até o momento em que passam a habitar a Clareira é um imenso vazio, sem qualquer referência. O único a guardar alguma reminiscência do mundo exterior é Thomas, o protagonista: quando em vigília ou em estado onírico a amnésia total dá lugar a flashs de memória sobre as experiências que ele testemunha nos laboratórios da corporação C.R.U.E.L. Essas reminiscências quando incorparadas às descobertas que Thomas faz quando está no Labirinto é que darão condições para que os jovens escapem do complexo.

Thomas e, posteriormente Tereza, a única do gênero feminino a fazer parte da comunidade, são os únicos que lembram do nome que receberam antes de chegar à 
Clareira. Todos os demais jovens foram nomeados por seus companheiros, justamente por não lembrarem sequer de seus nomes. A corporação realiza neles uma espécie de lobotomia química destituindo-os de suas memórias e consequentemente de suas indentidades. Essa condição mostra a corporação C.R.U.E.L. enquadrada na dimensão de um poder normatizador, que valendo-se da salvação da espécie humana como justificativa para suas ações cria normas eticamente discutíveis e procedimentos repressivos, dentre os quais o sequestro e o concentracionismo. Nesse processo, a memória ausente - e imposta pela corporação coerciva - se mostra, portanto, como poderoso instrumento de objetificação e exploração do outro, na medida em que produz uma existência em branco, a ser preenchida pela vida na Clareira. A Clareira, por sua vez, não passa de mero fetiche, na medida em que encobre a condição de ratos de laboratório a que realmente os jovens estão sujeitos.

Mas, apesar da amnésia que assola os jovens a memória é imprescindível em Correr ou Morrer seja por sua ausência, seja por sua presença. Sem ela não é possível nenhum acesso ao conhecimento do que existe além do Labirinto e sem conhecer o que há além não é possível encontrar a saída. Para os garotos o complexo figura, portanto, como uma espécie de cintilação da caverna platoniana. Por esse motivo em Correr ou Morrer a luta dos jovens é por ultrapassar o Labirinto porque isso significa a possibilidade de descobrir quem são e o que há para além do universo que conhecem, por mais terrível que seja a realidade a ser descortinada.

Mas a memória também se faz presente na forma de uma metáfora da memória como suporte. Em The Mazze Runner, assim como em outras distopias com protagonismo de jovens adultos, como as narrativas das séries Jogos Vorazes, de Suzanne Collins, e Incarceron, de Catherine Fisher, há um momento em que para sobreviverem ou alcançarem a saída do ambiente concentracionário os personagens necessitam imaginar a geografia hostil em torno deles como se vista de cima, como uma maquete, um tabuleiro de jogo ou um enigma, em cujo padrão podem ser encontradas pistas que possibilitarão a saída, capaz de garantir a fuga.

Desse modo, para conseguirem dominar o Labirinto os adolescentes constroem com minúsculos gravetos retirados do ambiente uma maquete da engenhoca. Desse modo, para fazer frente ao que permanece desconhecido e na ausência de outras tecnologias desencobridoras a maquete, na condição de miniatura, se apresenta como mediação e 
tradução. É perscrutando através da maquete que os garotos conseguem finalmente compreender parte dos segredos por trás dos muros do Labririnto e decodificar seu enigma. $\mathrm{O}$ desconhecido deixa de ser assim menos quimérico - como a vida. Nesse processo, vale ressaltar ainda a potência do impulso mimético, que fortalece a relação entre a leitura do texto e o universo juvenil, aproximando realidades.

\section{Do instinto de rebanho ao instinto de resistência: relações em The Maze Runner}

Thomas é um personagem marcado pela afirmação da vida. Em Correr ou Morrer ele torna-se um corredor e descobre várias pistas no Labirinto, que poderão abrir caminho para o escape. Paralelo às elucidações ele tenta convencer os companheiros da necessidade de deixar o complexo para que possam descobrir quem são e encontrar um mundo em que não sejam perseguidos por monstros. Mas a memória ausente, a acomodação e a presença de um medo castrador que permeia a constituição dos outros jovens, se colocam como barreira entre o protagonista e seus propósitos.

Segundo Laura Miller (2010, p.6) em narrativas distópicas para jovens adultos, produzidas nas últimas duas décadas o protagonista sempre apresenta a constituição de alguém que no interior de uma determinada comunidade ou grupo logo se mostra um desajustado, ou é um indivíduo apático que se transforma em ativo, ou alguém que se depara com uma incongruência antes vista pela comunidade ou grupo como natural e aceitável e se rebela contra essa incongruência: logo o herói funcionará como uma rachadura em uma parede lisa. Correr ou Morrer não foge a esse último paradigma.

De qualquer modo, independente do caminho tomado pelo herói abre-se uma fenda na realidade mostrada pela narrativa. Esse protagonista pode ser autóctone ou recém ingresso na comunidade, como é o caso de Thomas que, repentinamente, ao acordar, se vê entre outros garotos totalmente desconhecidos e, como eles, confinado em um lugar hostil, desprovido de sua identidade, uma vez que está totalmente amnésico e, inicialmente, sem qualquer noção do que deve fazer ou como se livrar da situação que parece interessante e favorável, mas que verdadeiramente é absurda e ameaçadora.

Desse modo, se a sociedade que move os interesses e disposições do grupo é uma falsa utopia, o herói descobre o engodo em seu próprio fundamento (MILLER, 2010, p. 6). Para esse herói ao contrário do que é apregoado na comunidade, fechada sobre si 
mesma, pode haver uma alternativa melhor lá fora, em algum lugar. As condições em que vive tornam-se cada vez mais insuportáveis, até que finalmente o herói, sozinho ou com outros companheiros, decide aventurar-se em terreno perigoso. É o que acontece com Thomas. Desde o primeiro momento em que se vê na Clareira e passa a conhecer o funcionamento do complexo Thomas questiona o lugar e se a permanência nele é de fato algo interessante e positiva.

É preciso ressaltar que no grupo em que Thomas é inserido nem todos os jovens coadunam da ideia de que é necessário escapar e procurar saber o que há além do Labirinto. Para alguns, especialmente os mais velhos, que habitam o lugar desde pequenos, a Clareira é um lar e mais que isso é um lugar onde eles se sentem relativamente seguros, desde que não transgridam as regras do Labirinto. Como eles não sabem o que há lá fora - e entre eles e o outro lado há o labirinto com verdugos, pensam que estar ali pode representar segurança e garantia de sobrevivência. Afinal estar ali significa estar vivo, ainda que a Clareira também seja uma prisão. Há um personagem, chamado Gally, que antagoniza com Thomas e representa totalmente essa posição em Correr ou Morrer.

Como Gally é uma liderança dentro do grupo, sendo um dos jovens que administra a segurança e as regras de convivência tenta impedir Thomas de agir, chegando a ordenar que ele seja detido em um bunker. O confronto entre os dois personagens estabelece uma dicotomia até certo ponto maniqueísta: Gally representa uma moral de rebanho, nos termos em que pensa Nietzsche (2001, p. 142), moral organizada segundo costumes, repetição, obediência, coerção, enquanto Thomas representa o "homem revoltado" (CAMUS, 2003), cuja insurgência justifica-se por sua imersão em uma situação absurda e injusta. Ao considerarmos estritamente a organização narrativa é justamente a revolta de Thomas e o comportamento autoritário de Gally, seguida da invasão destruidora dos verdugos à Clareira, que deitam fora o espelhamento desse espaço no paradigma da solarpunk fiction, paradigma em que não há lugar para a catástrofe.

É no limiar dessa relação e contra o instinto de rebanho que destaco o instinto de resistência como sendo também um fundamento predominante nas distopias, em particular nas distopias que envolvem jovens heróis. Esse instinto de resistência é nuclear para o desenvolvimento das ações e deflagra e alimenta o conflito da narração. A impulsividade e a rebeldia, condições comuns ao sujeito nessa fase da vida, organizam o contorno do "homem revoltado". A apreensão do absurdo é particularmente interessante 
nessa caracterização, sobretudo ao aproximarmos o instinto de resistência ao conceito camusiano. Entre os comentadores do ensaio de Camus é recorrente a ideia de que o absurdo - como lugar da falta de sentido e de coerência - é o ponto de partida em $O$ Homem Revoltado e a principal conexão entre este e $O$ Mito de Sísifo.

O absurdo tem lugar nas coisas fora de lugar. Mas não há absurdo sem absurdamento - o espanto diante do absurdo. Ao comentar essa perspectiva presente em O Mito de Sísifo diz Vanessa Martins (2009, p. 14) que o absurdo proposto por Camus reside "numa tomada de consciência de uma injustificação da realidade". Estar no absurdo - ou absurdar-se - é perceber-se com um "mal-estar diante dos semelhantes. Estrangeiro. Inimigo de si mesmo e dos outros. Quem entra no absurdo apercebe-se de uma falta de sentido, mas resiste, persiste, insiste. A vida torna-se infundada, cada vez é mais inumana, menos sentida e com menos sentido" (MARTINS, 2009, p, 15).

Esse mal-estar é instituído em Thomas na medida em que nele a inadequação da vida na Clareira é muito mais profunda do nos outros personagens e a percepção de que há uma vida "lá fora", cujo acesso vale a pena buscar a despeito dos perigos e incertezas que cercam a demanda, se tornam o elã de suas ações. O sentido de orfandade, de abandono e de deriva, presente em todos os outros personagens e que se constituem em aspectos que nutrem a condição de um "ser interditado", se apresenta ao protagonista como inaceitável e é justamente essa percepção que o leva à resistência. É contra o absurdo de uma existência sem memória, sem um antes ou possibilidade de um depois, que Thomas tenta inutilmente ponderar com Gally: apenas após a conclusão das ações de Correr e Morrer - e, portanto, já em Prova de Fogo - é que Gally será exposto à realidade catastrófica pós-Labirinto e com isso virá a sua adesão à resistência.

A título de conclusão vale destacar ainda que o instinto de resistência, em Maze Runner, é alimentado por uma ética que rechaça a dominação. A constituição de Thomas fortalece esse processo. Na trilogia composta para o cinema, cuja culminância se dá com A cura mortal, vemos que o cerne dessa ética reside no absoluto respeito às escolhas, especialmente quando estas envolvem auto-sacrifícios. Nesse sentido, o paradigma da distopia é bastante eficiente ao dar destaque a essa ética.

Em uma dicção benjaminiana, para Leomir Cardoso Hilário, uma distopia pode ser compreendida como aviso de incêndio: "o qual, como todo recurso de emergência, busca chamar a atenção para que o acontecimento perigoso seja controlado, e seus efeitos, 
embora já em curso, sejam inibidos" (HILÁRIO, 2013, p. 202) e, por isso mesmo, pode se converter em uma poderoso modo de leitura de questões da atualidade. As distopias direcionadas aos jovens, não deixam de cumprir esse papel, na medida em que tem destacado nas décadas que estão no limiar entre os séculos XX e XXI, a disseminação de formas de descarte do outro, de processos genocidas de natureza diversa ou a naturalização de eficazes mecanismos de mordaça ideológica, a serviço de interesses específicos, estatais e/ou corporativos.

\section{Referências:}

BOOKER, Keith. Dystopian Literature: A Theory and Reserarch Guide. Westport/Londres: Greenwood Press, 1994

CAMUS, Albert. O homem revoltado. Tradução de Valérie Rumjanek. Rio de Janeiro: Record, 2003.

CEIA, Carlos. Vai alto o romance: $O$ meu anjo Catarina, de Alexandre Pinheiro Torres. Ciberkiosk, $\mathrm{n}^{\circ} 4$ (Dezembro de 1998). Disponível em http://www.uc.pt/ciberkiosk/. Acesso em 23 de Abril de 2004.

DASNHER, James. The Maze Runner. Delacorte Press, New York, New York, 2009

NIETZSCHE, Friederich. A gaia ciência. Tradução de Paulo César de Souza. São Paulo: Companhia das Letras, 2001.

HILÁRIO, Leomir Cardoso. Teoria crítica e literatura: a distopia como ferramenta de análise radical da realidade. Anuário de Literatura, Vol. 18, n.2, p. 201-215, 2013.

LODI-RIBEIRO, Gerson. Prefácio. In: (org.) Solarpunk: histórias ecológicas e fantásticas em um mundo sustentável. São Paulo: Draco, 2012.

JAMESON, Fredric. As Sementes do Tempo. Tradução de José Rubens Siqueira. São Paulo: Ática, 1997.

MARTINS, Vanessa Mendes. Para uma Compreensão da Violência e do Compromisso no pensamento de Albert Camus. Dissertação (Mestrado). Unidade de Artes e Letras, Universidade da Beira Interior, Covilhã, 2009.

MCHALE, Brian. Constructing Postmodernism. London: Routledge, 1992.

MILLER, Laura. Fresh Hell. The New Yorker. 14 \& 21 de junho de 2010. Berverly Hills. Disponível em https://www.newyorker.com/magazine/2010/06/14/fresh-hell-lauramiller. Acesso em 14 de julho de 2019. 
MOYLAN, Tom. Scraps of the Untainted Sky: Science Fiction, Utopia, Dystopia. Westwiew Press, 2000.

MOONEY, Patrick. The Possibility of Utopia. In: Http://Www.Geocities.Com/Athens/Olympus/5599/Literature/Utopia.Html. Acesso em 12 de Novembro de 2003.

RODRIGUES, Paula Martins. A narrativa distópica juvenil: um estudo sobre Jogos Vorazes e Divergente. Dissertação (Mestrado). Programa de Pós-Graduação em Letras, Pontifícia Universidade Católica do Rio Grande do Sul: Porto Alegre, 2015.

SARMENTO-PANTOJA, Tânia. O paraíso extraviado: elementos neo-utópicos e distópicos em Pessach, a travessia, A festa e A terceira margem. Tese (Doutorado). Programa de Pós-Graduação em Estudos Literários, Faculdade de Ciências e Letras, Universidade Estadual Paulista Júlio de Mesquita Filho, Araraquara, 2005.

SCHMEINK, Lars. Biopunk Dystopias: Genetic Engineering, Society and Science Fiction. Liverpool University Press, 2014a

SCHMEINK, Lars. Biopunk 101. SFRA Review, 309, 2014b, p. 31-36. Disponível em https://www.academia.edu/8407432/Biopunk_101. Acesso em 14 de julho de 2019.

\section{Filmografia:}

Maze Runner (USA), Maze Runner: Correr ou Morrer (BRA/PRT). 2014. Direção: Wes Ball. Roteiro: Noah Oppenheim, Cor. 112m.

Maze Runner: The Scorch Trials (USA), Maze Runner: Prova de Fogo (BRA) ou Maze Runner: Provas de Fogo (PRT), 2015. Direção: Wes Ball. Roteiro: T.S. Nowlin. Cor. $131 \mathrm{~m}$. 